\title{
The Impact of Elaborated Feedback on Competency Assessment of IT Professionals
}

\author{
Elena-Alexandra TOADER, Mircea-Alexandru LUNGU \\ Bucharest University of Economic Studies, Bucharest, Romania \\ atoader22@yahoo.com,mircea.lungu@ie.ase.ro
}

Feedback represents an important component in the process of assessing the competencies of the IT professionals as it allows to evaluate their performance and helps their managers to personalize the learning content according to employees' needs and profiles. In the current paper we propose a computer-based formative feedback framework that provides personalized feedback for the technical employees. Extensive research has been carried out focusing on formative assessment aspects that includes the elaborate feedback. An online competency assessment tool was designed and it is going to be implemented in order to measure the professionals' performance in software organizations. The subjects of the study are going to be software developers, working in departments of IT Romanian companies. Their performance is going to be evaluated through the competency-based assessment tool. At the end of the assessment process, an elaborate feedback is provided in order to improve their current level of competency acquired. The current paper reveals the role of the computer-based formative assessment within software organizations as well as the importance of an elaborate feedback that can improve the employees' knowledge and skills.

Keywords: Elaborated Feedback, Formative Assessment, IT Competency, IT Professionals

\section{1} Introduction

Nowadays the computer-based formative assessment is considered a component of modern education. It is not used only in selfassessment processes, but also in complementing the traditional methods of evaluations of the employees' performance.

The IT competency assessment is be used to measure and appraise technical employee performance. Assessments are often used to formulate judgments about performance in order to select, classify or certify and is known as summative assessment. Assessments can also be contribute to employee learning, which is referred to as formative assessment.

The purpose of formative competency assessments is to conduct learning activities by generating feedback on employees' performance. Feedback is an important part of the assessment process as it allows employees and managers to take actions to improve the current level of acquired competencies.

Feedback provides to the employees the information that can be used to close the gap between actual performance and desired levels of performance. In this study, feedback is defined as information about the actual state of competency level that employees possess, which is provided after responding to a testlike event. Computer-based formative assessment is considered effective by improving the competencies of the employees and providing the individualized feedback independent of time or place.

The aim of the feedback is to provide information about the current level of competency acquired (skills and knowledge) and as well to improve the employee' learning in order to be more competitive and in line with the organizational goals.

In this paper we present the results of an experimental study where we design and implement an elaborated feedback in a competency-based assessment tool that is going to evaluate the IT competencies of the technical employees that are working in Romanian IT organizations. The results of our study outlines the advantages of taking into account the elaborated feedback at the end of the assessment process. 


\section{Theoretical Framework}

\subsection{Computer-based Formative Assess- ment}

The computer-based formative assessment stimulates and provides direct learning by providing a feedback on actual performance. The feedback informs the IT professionals about the actual state of performance, how it can be improved and how to bridge a performance gap [1].

The main advantage of using computer-based formative assessment is that they can provide the individualized feedback independent of time or place [2]. When a large number of employees are taken the assessment, the automated provision of feedback is representing an optimal solution, improving the deadlines and workload pressure. The effective feedback should contain information like: current performance and the intended level of performance. Using answering models constructed in advantage is easily to generate an objective, immediate and appropriate feedback. [3]

The research conducted by [4] shows that student are more likely to follow a computermediated feedback than a person- mediated feedback. This is given by the objectivity of the feedback provided by the computer that remains unnoticed by others.

In this research, the computer-based formative assessment is conceptualized starting from the model developed by [5] and adapting it at the competency assessment process of the IT professionals. The model is containing five stage for the process of receiving the feedback after a test-like event. The first stage is represented by Employees' initial state. The initial state is characterized by cognitive aspects and motivational beliefs [6]. The test-like event is composed by questions related to the knowledge and skills that employee's possess (second stage). The response of the employee is shown in stage 3. At the end of the test, the elaborated feedback is provided. Next, employees are improving their performance by accessing and acquiring the feedback (stage 4). The performance of the employees can result in adjustments (stage 5) and lead to the initial stage (stage 1). The effect of the computerbased formative assessment is defined as the differences between stage 5 and stage 1 . In Figure 1 is described the computer-based formative assessment model.

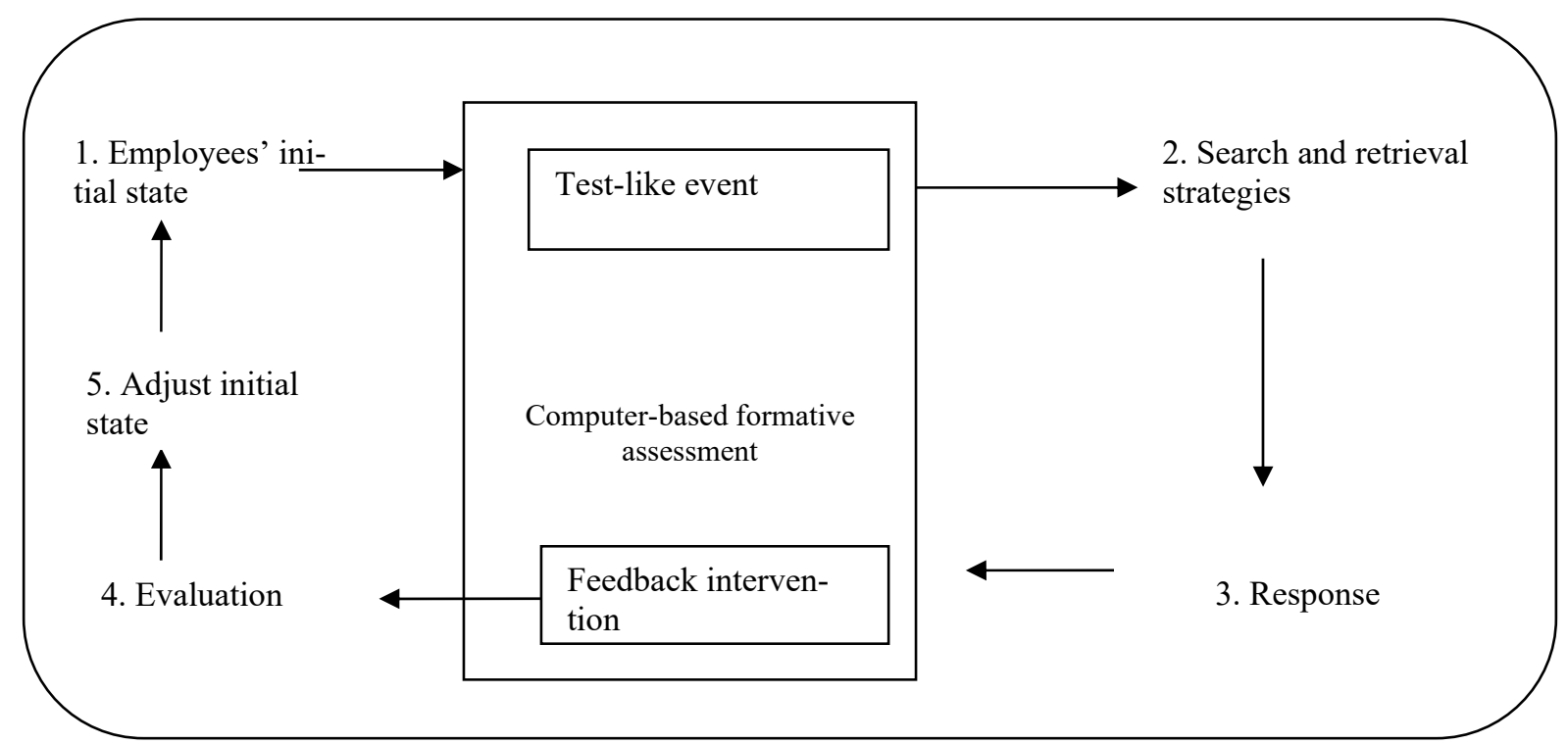

Fig. 1. Conceptualizations of CBFA based on the five-stage model (Adapted after [7])

\subsection{Feedback}

Feedback can be defined as a practice of formative assessment, which attempts to close the gap between current and desired performance [8]. Feedback is primarily used in order to improve knowledge and performance. Hence it is typically provided for false responses 
There are three important properties of feedback according to [9]: the type of feedback, the level of feedback and timing of feedback. Also there are different feedback types: knowledge of results, knowledge of correct response and elaborate feedback. In case of knowledge of results, the feedback is unspecific, the feedback is given only if the answer is correct or incorrect. In case of knowledge of the correct response, the feedback is given if the responder gives the right response. The elaborate feedback contains a large variety of feedback: explanations of correct or incorrect responses, links to be accessed for further reading, suggestions or a combination of all [9]. Elaborated feedback is preferred to simple ones at least for assessment that requires higher-order cognitive processes [10]. The feedback is used in combination with specific cognitive processes require reading strategy instruction [11].

The relationship between feedback and learning process is not positive each time [9]. There has been made several studies that reveal inconsistency and contradictions [12] [13]. The main aim of the feedback is to provide ways of improving learning taking into account the employee' performance [9].

According to other studies, feedback interventions can affect the learning processes at different levels [14] [15]. There are cognitive, metacognitive and motivational functions. The cognitive and metacognitive function is when feedback provides information about the nature of performance gap. Also can offer strategies to resolve it [14]. The motivational function is when feedback lead to more efficient task strategies that acquires higher motivation [15].

Formative feedback refers to information communicated to the employee that is intended to modify the behavior and thinking for the purpose of improving competencies [9].

\section{Research Methodology}

This study focuses on the implementation of an elaborate feedback within a web-based assessment application. Based on the five-stage model presented in Figure 1, the computer- based formative assessment outlines the relations between the initial competency level of an employee by taking a test-like event and evaluation result (feedback generation).

The application assesses the competencies found in the competency model defined by [16]. The competency model contains 15 PM competencies grouped by categories: methodical, personal-social, strategicorganizational.

The employee' initial state is containing information related to the employee, such as: first name, last name, the hire date, the department, the position, the manager name and information about the previous assessments that employee taken.

The test-like event contains 15 questions, each of them being linked to a competency. Each question is considered to be an assessment item. The 15 closed questions offer an easy way to summarize the results. Each assessment item has 4 responses with a unique answer that are linked with a performance indicator from the ontology proposed by [17]: awareness, familiarity, mastery, expertise.

Based on the combination of possible answers and considering the classification of performance indicators, a formative feedback is going to be provided to the responder. First, a keyword mapping the competency ontology proposed by [17] is defined for each answer. Each keyword is matching a feedback link that contains a web resource where some recommendations will be made in order to improve the responder's degree of specific competency.

The link is containing information based on learning activities that the responder has to conduct in order to be more competitive, to improve his knowledge and to be in line with the organizational goals [18].

The feedback could be downloaded by the employee who takes the assessment and it will be generated by the system administrator for each response of the assessment item, according to the keyword that match the competency ontology.

The role of the formative assessment in the assessment of IT competency process is 
about gathering information about IT professionals' performance and giving feedback in order to contribute to employee learning and improving the current level of competency acquired.

\section{The Computer-Based Formative As- sessment Tool}

The aim of the research is to design a computer-based formative assessment tool which is going to evaluate the competencies of IT professionals, outlining an elaborate feedback at the end of the evaluation. The application is developed in PHP programming language and the database in MySQL tool.
In Figure 2 is described how the feedback is generated to the user. At the end of the assessment process, the employee is receiving a results page containing the response given to each question and a feedback link. The results page is specific to the employee that has all the information stored in database. Based on the given answer to all the questions from the test-like event, according to a keyword, a feedback is generated. The feedback contains a web resource that the employee can access in order to improve his current competency level.

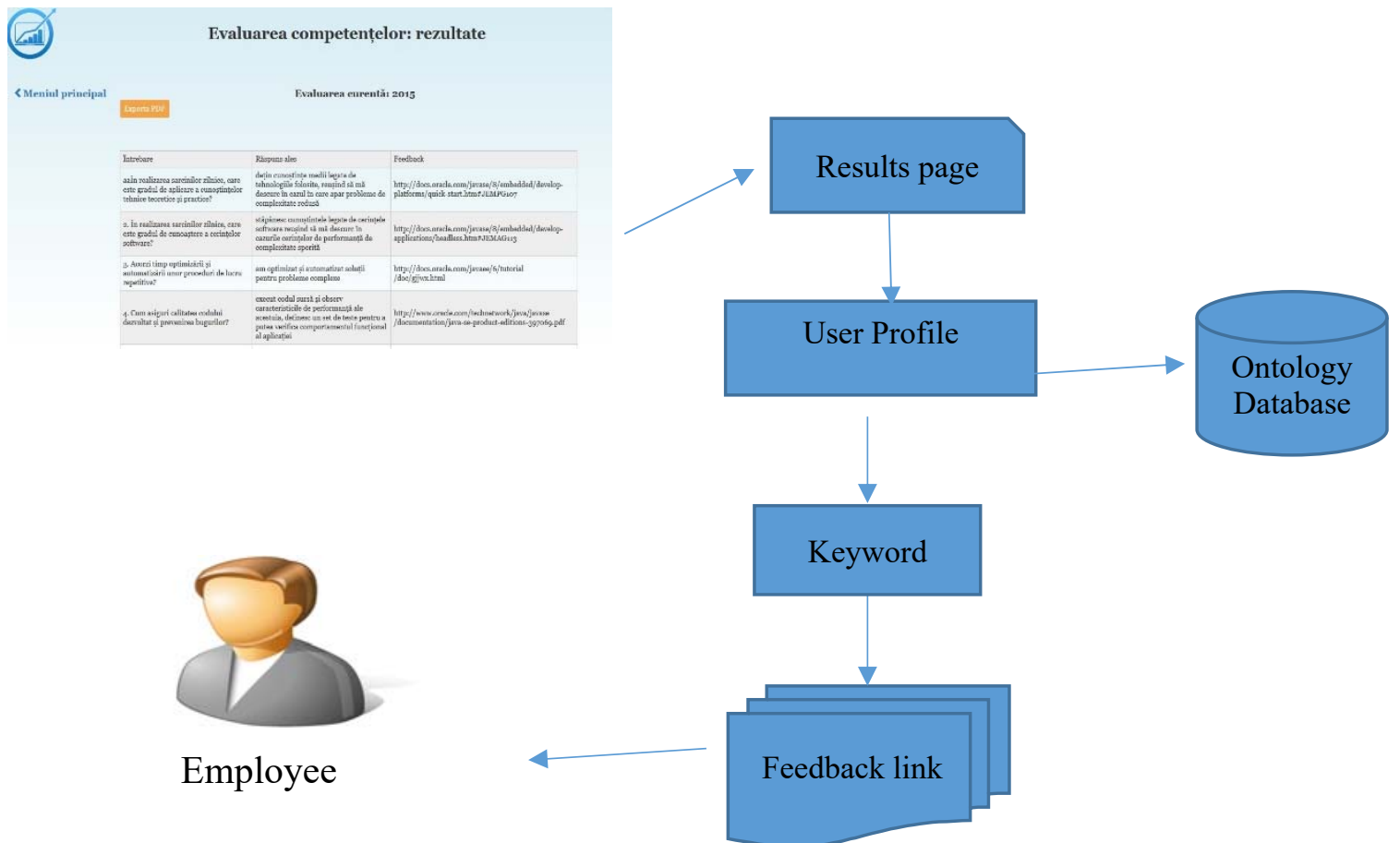

Fig. 2. The generation of feedback

The database is containing information about the competency ontology concepts defined by [17], the employee's information, the assessment items questions, the assessment items answer, the score, the keyword corresponding to each answer, the feedback attached to keyword, the response provided by the employee during the evaluation for each assessment question.
The competency ontology combines concepts of knowledge, skills, and target population and performance indicators for IT domain. It also provides ways for modeling IT competencies, for defining competencies and for evaluating criteria on skill performance [17]. The concepts of the ontology are stored in the database, the tables and their relationships being outlined in Figure 3. 


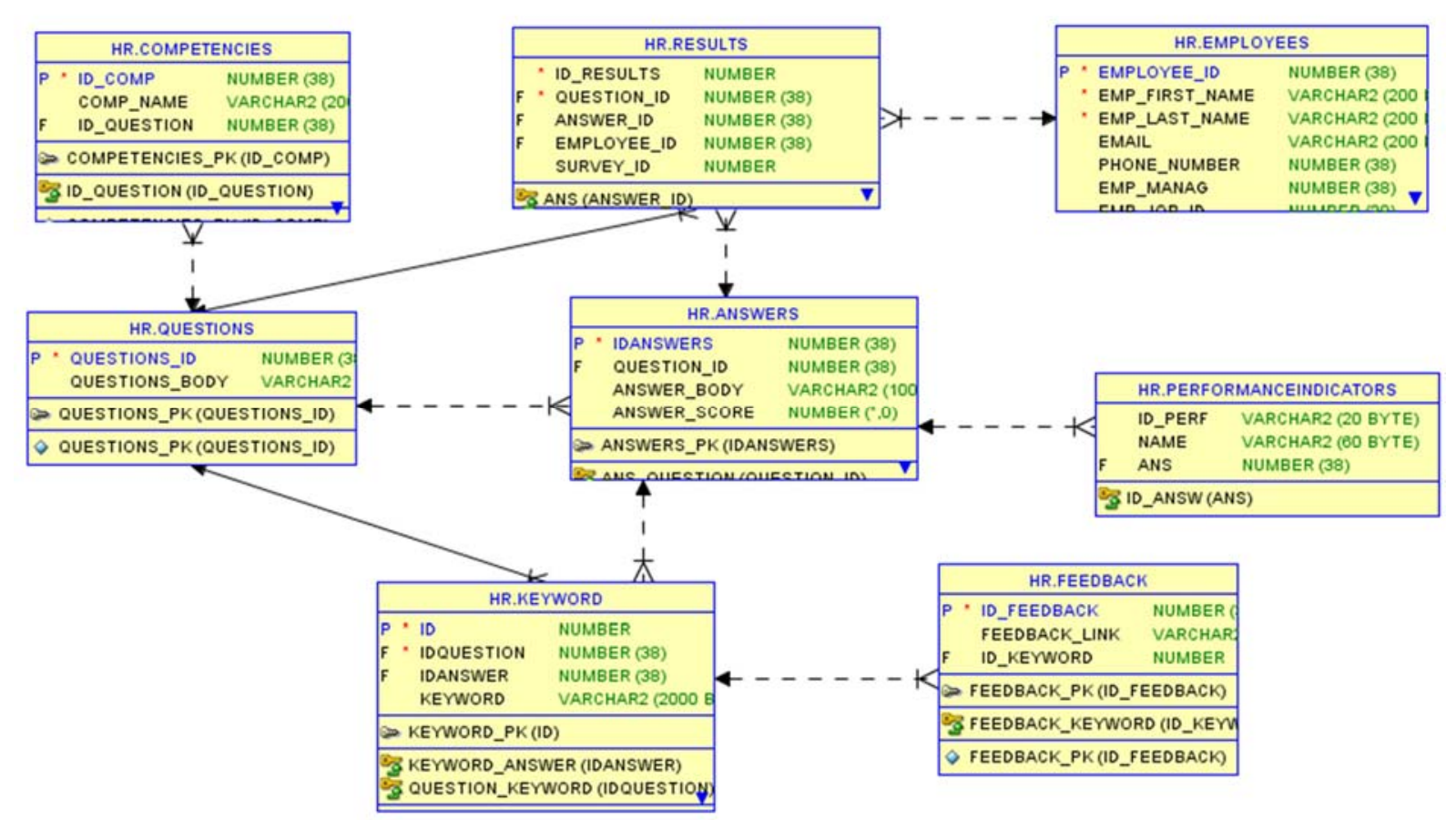

Fig. 3. Database structure

The competencies table contains all the 15 PM competencies from the competency model defined by [17]. The Questions table contains the text of the questions, each of them being linked to a competency from the Competencies table. Each question is considered to be an assessment item and has 4 possible responses that are stored in the Answers table. Each answer contains a performance indicator taken from the Performance Indicator table and a Keyword from Keyword table. The keyword is mapping the competency ontology. It is linked to the Feedback table which contains a feedback link.

The keyword and the feedback can be modified by the administrator of the application. The feedback contains a useful web resource that the employee can access in order to improve his competency level. The Results table stores all the answers given by the employees to all assessment items and the Employees table stores information related to the employees: first name, second name, hire date, email, phone, manager, department and position.

The application is based on two modules for each participant at the workflow: the employee, and the system administrator. For all the modules the login page is required. The employee can edit his personal information, can add or edit attended coursed, can take a new assessment and select an answer for each assessment item. Can view at the end of the assessment test a result page containing the answer given at each question and a feedback link containing a web resource. The employee can also see the results from previous assessments.

The Administrator of the application can select an assessment item and for a performance level selected can add or modify the keyword and the feedback link. In Figure 4 is described a use case for the Employee and Administrator module. 


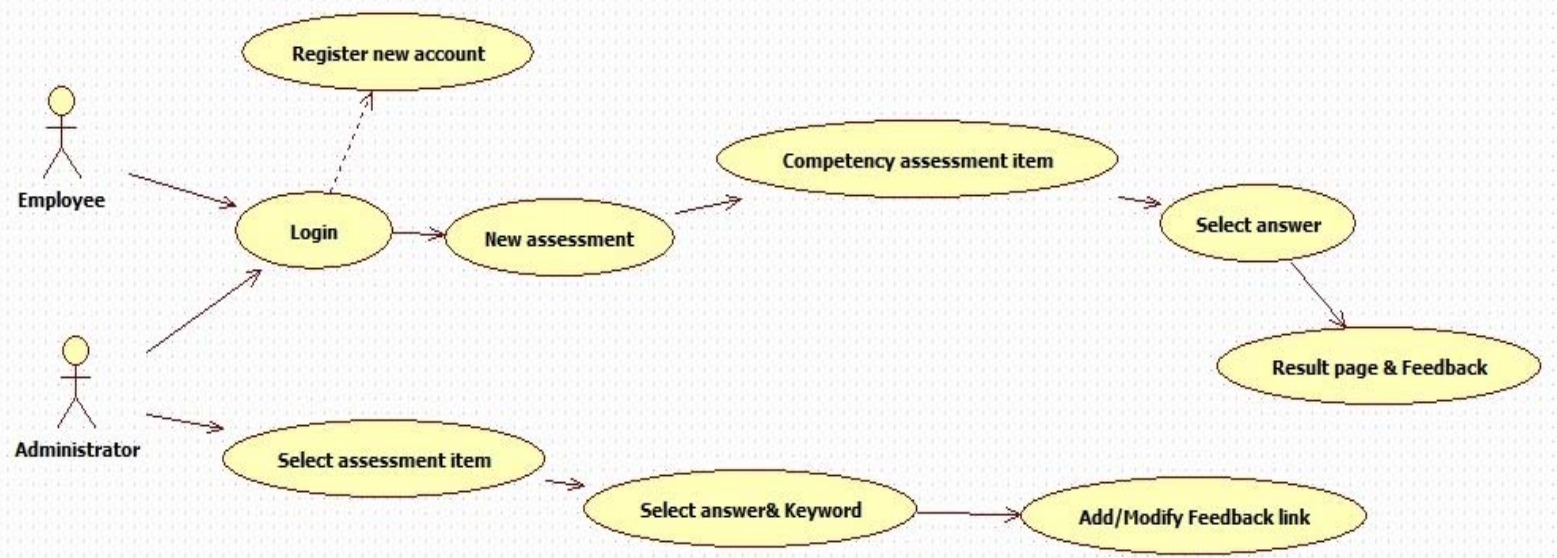

Fig. 4. A use case for Employee and Administrator modules

The elaborate feedback within the assessment tool is outlined in the results page that the employee receives at the end of the evaluation process. The results page contains a table with the question, the corresponding answer for the question and a feedback containing a web resource. By accessing the web re- source, the employee can take some recommendations which are going to improve the responder's degree in a specific competency. The feedback table can be downloaded by the employee (the download can be made in the Portable Document Format). In Figure 5, the results page is presented.

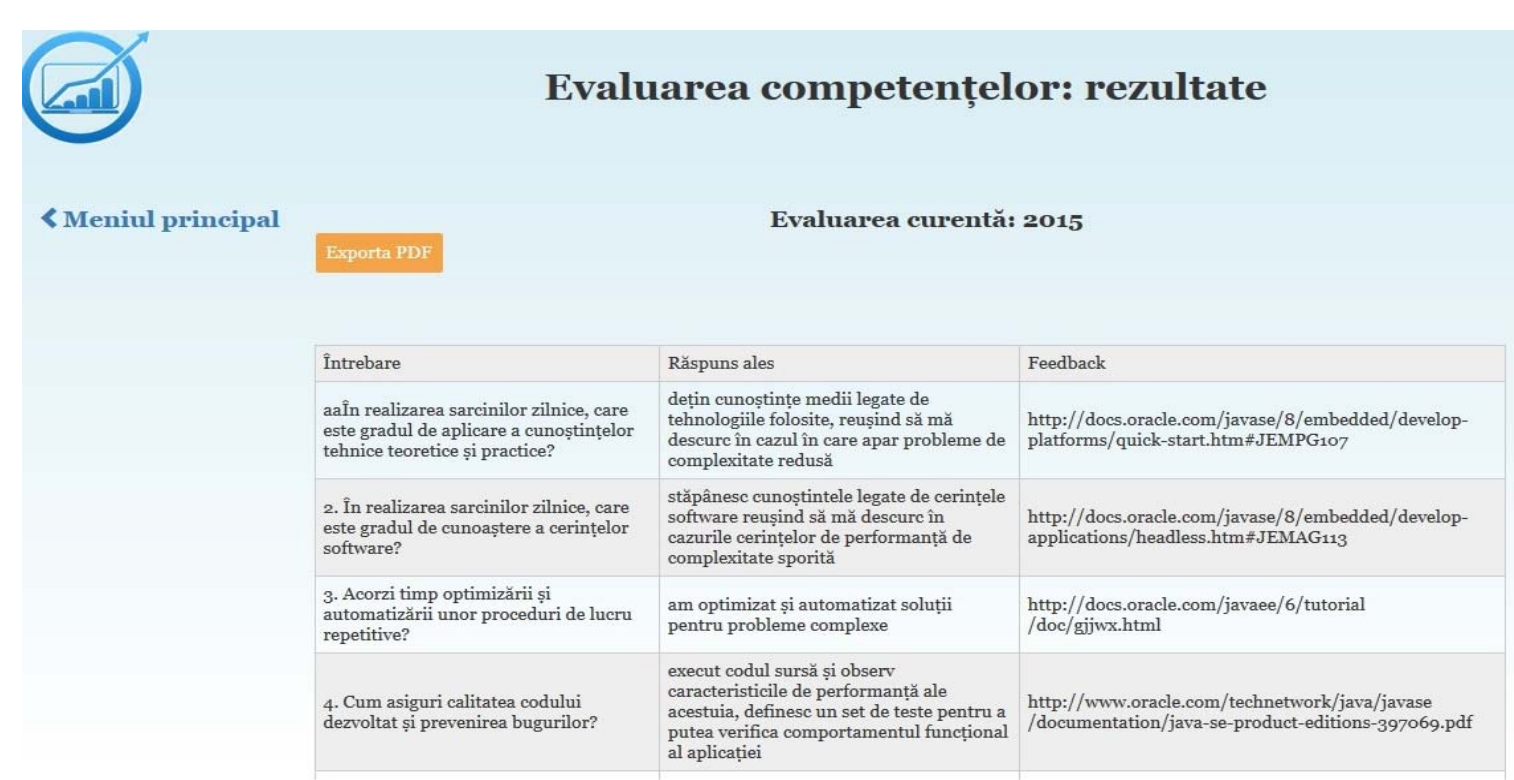

Fig. 5. The results page

The feedback link is given according to a keyword mapped to the competency ontology. Each keyword is associated with a link that can be modified as well by modified by the administrator of the application. The administrator of the application can select an assessment item and can add or modify the keyword and the feedback link. Figure 6 shows the interface where the keyword and feedback is configured by the administrator of the application. 


\section{Editare feedback}

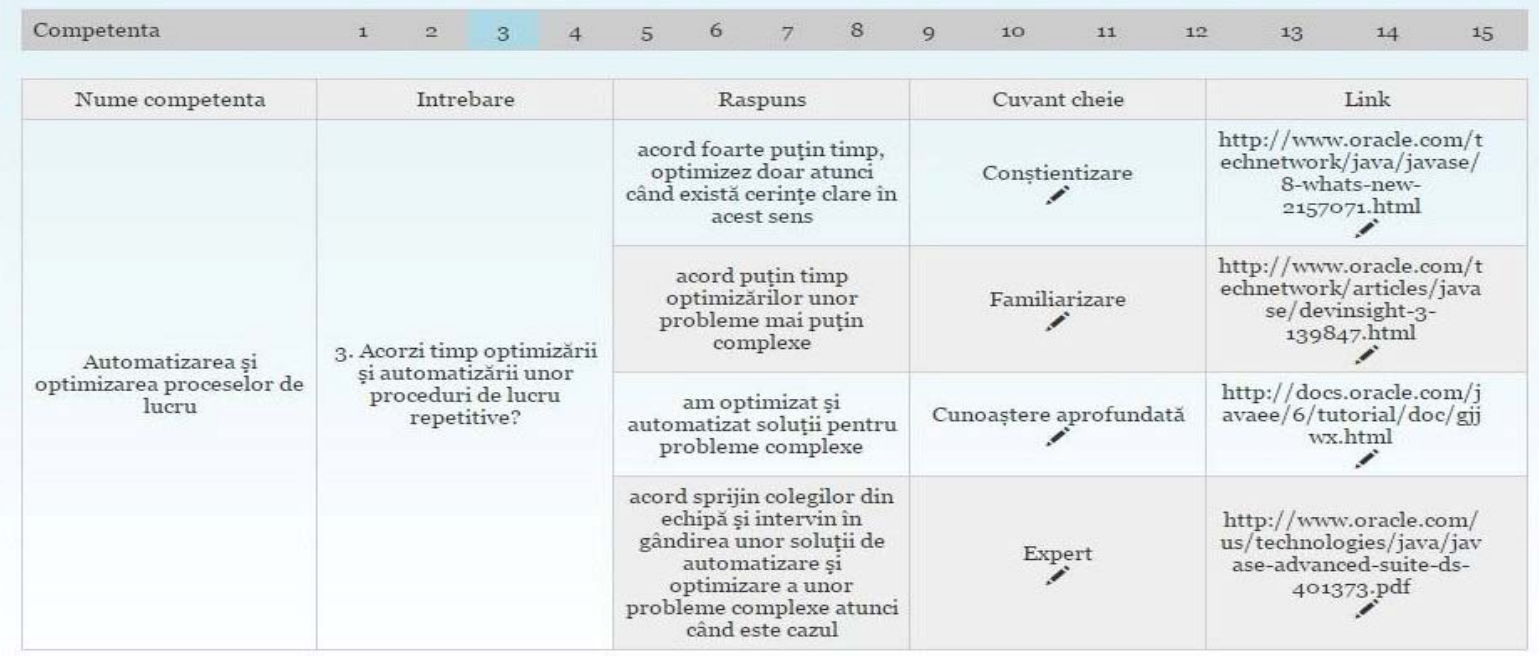

Fig. 6. Feedback administration screen

\section{Conclusions}

In the competency assessment process, the formative assessment should facilitate the employees to gain a briefly knowledge about the desired levels of performance and understanding, employees and managers to compare the actual level of performance with the prescribed standards and also to develop learning activities in order to close a performance gap.

In this study, a five-stage model of computerbased formative assessment has been explored and relationships between employee response, item difficulty, and feedback has been examined. Feedback is given according to a keyword that maps the competency ontology defined the authors in previous studies. Feedback is containing a web resource that must be accessed by the employees in order to improve the current level of competency (skills and knowledge), in order to be more competitive, and to be in line with the organizational goals.

A limitation of our study is that the assessment tool was not implemented yet in a Romanian IT organization, so no relevant results are available. Another limitation is that the employer module has not been developed yet.

Future research should be directed through developing open questions for the evaluating the assessment items, through developing the feedback using a crawler will search in the World Wide Web the appropriate links that the employees must consult after the assessment process.

Based on the results the computer-bases formative assessment is recommended to take into account in the competency assessment process. The assessment tool based on it should provide objectivity and validity of the evaluation process and should also provide new ways of learning activities for the employees.

\section{Acknowledgements}

This paper was co-financed from the European Social Fund, through the Sectorial Operational Programme Human Resources Development 2007-2013, project number POSDRU/159/1.5/S/138907 "Excellence in scientific interdisciplinary research, doctoral and postdoctoral, in the economic, social and medical fields -EXCELIS", coordinator The Bucharest University of Economic Studies. 


\section{References}

[1] J. Hattie and H. Timperley, "The power of feedback", Review of Educational Research, vol. 77(1), 2007, pp. 81-112

[2] T. Buchanan, T, "Using the World Wide Web for Formative Assessment", Journal of Educational Technology Systems, vol. 27(1), 1999, pp. 71-80

[3] C. Timmers, A. Walraven, B. P. Veldkamp, "The effect of regulation feedback in a computer-based formative assessment on information problem solving", Computers \& Education, vol. 87, 2015, pp. 1-9

[4] A. N Kluger and S. Adler, "Person-versus computer-mediated feedback", Computers in Human Behaviour, vol. 9(1), 1993, pp. 1-16

[5] R. L. Bangert-Drowns, C. Kulik, M. Morgan, "The instructional effect of feedback in test-like events", Review of Educational Research, vol. 61, 1991, pp.213-238.

[6] F. M. Van der Kleij, R. Feskens and T. J. Eggen, "Effects of feedback in computerbased learning environment on students' learning outcomes: a meta-analysis", In Paper presented at the NCME, 2013, San Francisco.

[7] E. H. Mory, "Feedback research revisited", In D. Johnsen (Ed.), Handbook of research on educational communications and technology, 2004, pp. 745-783 Mahwah: Erlbaum Associates.

[8] D. R. Sadler, "Formative assessment and the design of instructional systems", Instructional Science, vol. 18, 1989, pp. 119-144.

[9] V. J. Shute, "Focus on formative feedback", Review of Educational Research, vol. 78(1), 2008, pp. 153-189.

[10] F. M. Van der Kleij, R. C. Feskens and T. J Eggen, "Effects of feedback in a computer-based learning environment on students' learning outcomes a metaanalysis", Review of Educational Research, vol. 20, 2015, pp.1-37

[11] H. W. Lee, K. Y. Lim and B. L. Grabowski, "Generative learning strategies and metacognitive feedback to facili- tate comprehension of complex science topics and self-regulation", Journal of Educational Multimedia and Hypermedia, vol. 18(1), 2009, pp 5-25.

[12] R. Azevedo and R. M. Bernard, "A meta-analysis of the effects of feedback in computer-based instruction", Journal of Educational Computing Research, vol. 13(2), 1995, pp.111-127.

[13] A. N. Kluger and A. DeNisi, "The effects of feedback interventions on performance: A historical review, a metaanalysis, and a preliminary feedback intervention theory", Psychological Bulletin, vol. 119(2), 1996, pp. 245-284.

[14] D. L. Butler and P. H. Winne, "Feedback and Self-Regulated Learning: A Theoretical Synthesis", Review of Educational Research, vol. 65(3), 1995, pp. 245-281.

[15] S. Narciss, Feedback strategies for interactive learning tasks. In M. D. M. J.M. Spector, J.J.G. van Merrienboer, \& M.P. Driscoll (Ed.), Handbook of Research on Educational Communications and Technology 3rd ed., 2008, pp. 125-144, Mahwah, NJ: Lawrence Erlbaum Associates

[16] C. N. Bodea, E-A. Toader, "Development of the PM competency model for IT professionals, base for HR management in software organizations", 12th International Conference on Informatics in Economy (IE 2013), Education, Research and business Technologies, Bucharest, April 2013

[17] C. N. Bodea, E-A. Toader, "Ontologybased modelling of the professional competencies - a comparative analysis", The 11th International Conference on Informatics in Economy (IE 2012), Education, Research and business Technologies, $\mathrm{Bu}-$ charest, May 2012, pp. 452-458

[18] E-A. Toader, "Competency-based assessment of IT professionals as a software organization tool", The $11^{\text {th }}$ International Scientific Conference eLearning and Software for Education (ELSE), Bucharest, April, 2015 


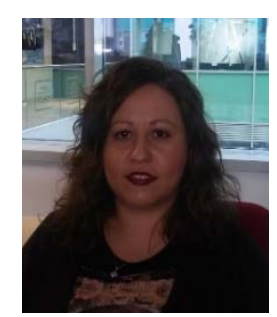

Elena Alexandra TOADER has graduated the Faculty of Cybernetics, Statistics and Economic Informatics of the Bucharest University of Economic Studies in 2008. She has graduated the Professional Master's Program in Economic Informatics at the Faculty of Cybernetics, Statistics and Economic Informatics of the Bucharest University of Economic Studies in 2010. She is a PHD Student at the Economic Informatics PHD School and the main field of interest is competency assessment methods.

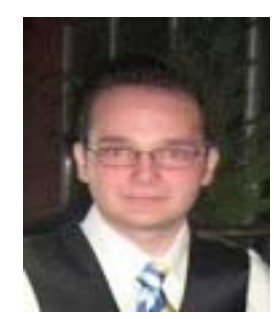

Mircea-Alexandru LUNGU has present occupation as a senior programmer and software developer at Global Group Consulting Division, an IT Company from Bucharest Romania. His scientific interests are based on economics and European funds. He is a PHD Student at the Economic Informatics PHD School and his main research projects are: software management and web crawlers. 